\title{
Drilling analysis of coir-fibre-reinforced polyester composites
}

\author{
S JAYABAL* and U NATARAJAN \\ Department of Mechanical Engineering, A.C. College of Engineering and Technology, \\ Karaikudi 630 004, India
}

MS received 17 June 2010; revised 5 August 2010

\begin{abstract}
An investigation has been carried out to make use of coir, a natural fibre abundantly available in India. Coir-polyester composites were prepared and their mechanical and machinability characteristics were studied. The short coir-fibre-reinforced composites exhibited the tensile, flexural and impact strength of 16.1709 MPa, 29.2611 MPa and 46.1740 J/m, respectively. The regression equations were developed and optimized for studying drilling characteristics of coir-polyester composites using the Taguchi approach. A drill bit diameter of $6 \mathrm{~mm}$, spindle speed of $600 \mathrm{rpm}$ and feed rate of $0.3 \mathrm{~mm} / \mathrm{rev}$ gave the minimum value of thrust force, torque and tool wear in drilling analysis.
\end{abstract}

Keywords. Taguchi method; thrust force; torque; tool wear; dynamometer.

\section{Introduction}

Natural fibres such as coir, cotton, flax and sisal have been used since historical times in a large variety of products, ranging from clothes to roofing of houses. Today, these fibre composites are appraised as ecofriendly materials owing to their biodegradability and renewable characteristics. The annual world production of coconut is about 42 million tons (MT), which would amount to almost 50 billion coconuts. Many aspects of the use of coir fibres as reinforcement in polymer-matrix composites are described in the literature. Coir products are assembled from their parts by joining methods; so, it is essential to study the drilling characteristics of coirpolyester composites.

Abrao et al (2007) studied the effect of tool material and geometry, machining parameters and their influence on the thrust force and torque during drilling of fibrereinforced plastics.

Godfrey et al (2006) presented a mathematical model for correlating the interactions of some drilling control parameters such as speed, feed rate and drill bit diameter and their effects on some responses such as axial force and torque acting on the cutting tool during drilling by means of response surface methodology. The results obtained show that the mathematical model was useful not only for predicting optimum process parameters for achieving the desired quality but also for process optimization.

Harish et al (2009) investigated the mechanical properties of randomly oriented coir composites mixed with

\footnotetext{
*Author for correspondence (jayabalsubbaian @ rediffmail.com)
}

epoxy resin and made suggestions for low-load applications. They assessed only the limited mechanical properties such as tensile strength, flexural strength and impact strength, and their work was limited from the machinability point of view.

Khashaba et al (2006) investigated the effects of the drilling parameters, speed and feed, on the required cutting forces and torques in drilling chopped composites with different fibre volume fractions. Using multivariable linear regression analysis, empirical formulas that correlate favourably with the obtained results were developed in their work.

Fernandes and Cook (2006) described the development of an empirical model of the maximum thrust force and torque produced during drilling of carbon fibre with a 'one shot' drill bit.

Monteiro et al (2008) evaluated structural characteristics and mechanical properties of coir fibre-polyester composites. They analysed variation of the flexural strength with the mass fraction of coir fibres and moulding pressure. The results obtained for flexural strength allowed the comparison of the technical performance of the composites with other conventional materials.

Palanikumar et al (2006) developed a mathematical model to predict surface roughness and tool wear in their work in order to study the main and interaction effects of machining parameters by regression analysis and ANOVA techniques and suggested the best procedure for modelling and optimization of process parameters.

Tsao and Hocheng (2007) presented the prediction and evaluation of thrust force and surface roughness concepts in drilling of composite material using candle stick drill in their work. The approach was based on the Taguchi method and the artificial neural network techniques. The 
experimental results indicated that the feed rate and the drill diameter were the most significant factors affecting the thrust force, while the feed rate and spindle speed contributed most to surface roughness.

In most of the works, the characterization study was carried out to evaluate mechanical properties, and drilling study was made on other than natural fibre-reinforced composites. As the development of natural fibre reinforced composites (NFRC) composites are growing now, this paper focused on the development of mathematical model for predicting thrust force, torque and tool wear in drilling of randomly oriented coir-fibre-reinforced composites. The drilling characteristics were studied for making quality holes and delamination free holes in coir composites. For obtaining these requirements, the thrust force, torque and tool wear must be studied and optimized. If the hole is made in an optimum set of conditions, cutting forces and tool wear will be minimum. This will lead to maximum material removal and less power consumption.

In this investigation, the coir-fibre-reinforced composite was fabricated using hand layup process. A series of experiments were conducted using CNC milling machine to drill the coir-polyester composites. A Kistler-make drill tool dynamometer was used to record the thrust force and torque. A Rapid I machine vision system from Customized Technologies (P) Ltd. was used to measure the tool wear.

\section{Preparation of specimen and mechanical tests}

The composite prepared in this study was a rectangular sheet of length $360 \mathrm{~mm}$, width $360 \mathrm{~mm}$ and thickness $3 \mathrm{~mm}$, made up of randomly oriented coir fibre composite material manufactured by the hand layup process. The composite was fabricated using green husk coir fibre of length $50 \mathrm{~mm}$ and content in weight of $19 \%$. For $100 \mathrm{~g}$ polyester resin, $1.5 \mathrm{~g}$ accelerator (cobalt octoate) and $1.5 \mathrm{~g}$ catalyst (methyl ethyl ketone peroxide) were mixed. After the fabrication, test specimens were prepared and they were subjected to various mechanical tests as per ASTM standards using Universal Testing Machine. The ASTM testing standards of ASTM-D 638, ASTM-D 790 and ASTM-D 256 were followed for tensile, flexural and impact strength, respectively. The prepared coir-polyester composites exhibited average values of tensile strength, flexural strength and impact strength of $16.1709 \mathrm{MPa}$, $29.2611 \mathrm{MPa}$ and $46 \cdot 1740 \mathrm{~J} / \mathrm{m}$, respectively. Scanning electron micrographs of the tested specimen after tensile and flexural tests are shown in figures 1 and 2.

\section{Experimental procedure and tool materials}

The three-axes Mtab-make Maxmill model CNC Vertical Machining Center was used to drill the coir-polyester composites using M42-grade HSS twist drills. M42 is a molybdenum-chromium-vanadium-tungsten high-speed steel alloy with an additional content of $8 \%$ cobalt. It is widely used in metal manufacturing because of its superior red-hardness as compared with more conventional high-speed steels, allowing for shorter cycle times in production environments due to higher cutting speeds or due to the increase in time between tool changes. This tool was supplied by Addison \& Co. Ltd.

For machining glass-fibre-reinforced polyester (GFRP) composites carbide drill bits or other hard drill bits are used. As the coir composites are very soft material, the conventional HSS tool was preferred. A Kistler-make dynamometer was used to record the thrust force and torque. It is a typical static cutting force measuring system consists of the dynamometer, a connecting cable and the multi-channel charge amplifier.

A Rapid-I machine vision system from Customized Technologies (P) Ltd. was used to measure the tool wear.

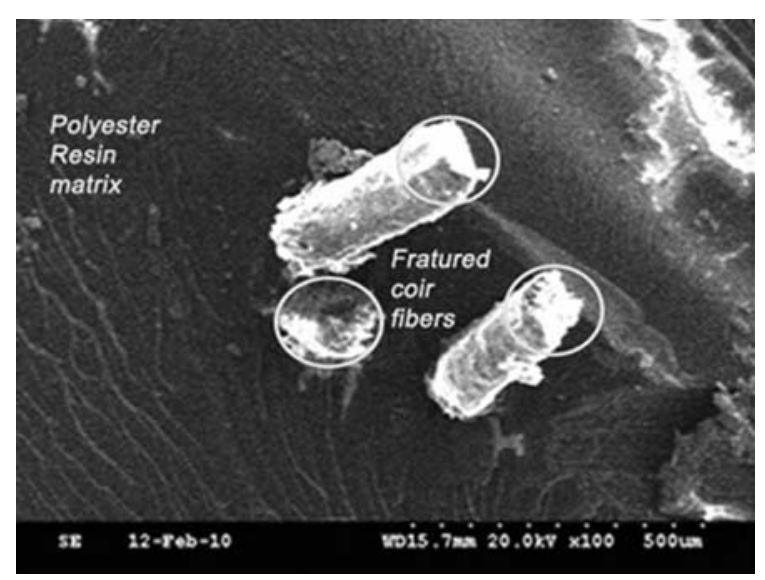

Figure 1. Scanning electron micrograph of coir-fibrepolyester specimen after tensile fracture.

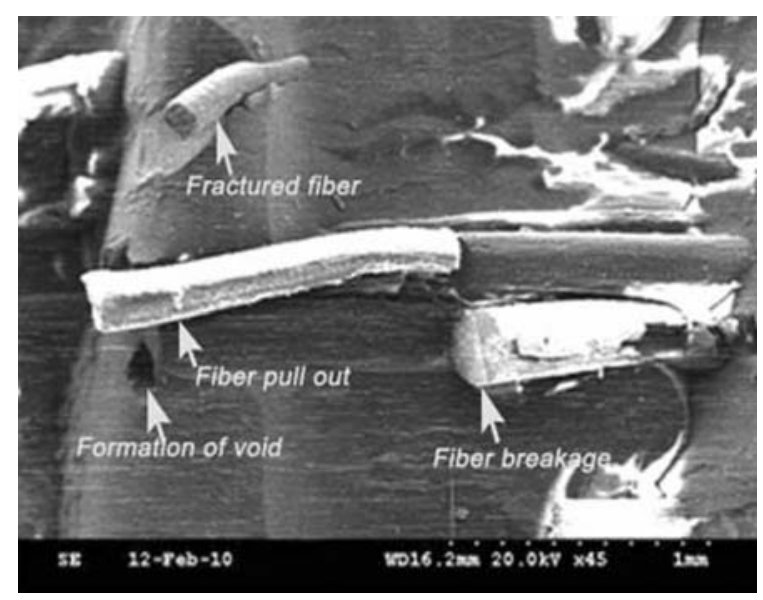

Figure 2. Scanning electron micrograph of coir fibrepolyester specimen after flexural fracture. 
Rapid-I Software comes with powerful graphical tools for enhanced measurements and inspections. Using the powerful graphical suite available in Rapid-I, the drafting of drill bit profile was created using a CAD package. After the drilling operation, again the tool profile was drawn. Differences between the two profiles were estimated with the on-screen digital micrometer tool to estimate tool wear.

\section{Design of experiments}

Design of experiments, or experimental design, is the design of all information-gathering exercises where variation is present, whether under the full control of the experimenter or not (Palanikumar and Davim 2008). The response variables, thrust force and torque were recorded for each run using drill tool dynamometer. The effect of the machining parameters is another important aspect to be considered. It may be seen that cutting speeds from 20 to $60 \mathrm{~m} / \mathrm{min}$ are usually employed, whereas feed rate values lower than $0.3 \mathrm{~mm} / \mathrm{rev}$ were frequent. Cutting speed is not a limiting factor when drilling polymeric composites, particularly with hard metals; therefore, the use of cutting speeds below $60 \mathrm{~m} / \mathrm{min}$ may be explained by the maximum rotational speed of conventional machining tools, since drill diameters above $10 \mathrm{~mm}$ are rarely reported in most of the literatures. Another reason for keeping cutting speeds below $60 \mathrm{~m} / \mathrm{min}$ may reside in the fact that higher cutting speed values led to higher cutting temperature, which in turn caused the softening of the matrix. The use of feed rates below $0.3 \mathrm{~mm} / \mathrm{rev}$ may be associated to the delaminating damage caused when this parameter was increased. Initially, optimization of cutting conditions was performed to check the adequacy of the levels. It was observed that the optimum operating conditions also lie within the levels assigned. Based on these results, the three levels of input variables were confirmed. The assignment levels of input variable are given in table 1 .

\subsection{Taguchi method}

Dr Genichi Taguchi of Japan developed a method for designing experiments to investigate how different parameters affect the mean and variance of a process performance characteristic that defines how well the process

Table 1. Assignement levels of process parameters.

\begin{tabular}{lcc}
\hline $\begin{array}{l}\text { Drill bit diameter } \\
(\mathrm{mm})\end{array}$ & $\begin{array}{c}\text { Spindle speed } \\
(\mathrm{rpm})\end{array}$ & $\begin{array}{l}\text { Feed rate } \\
(\mathrm{mm} / \mathrm{rev})\end{array}$ \\
\hline 6 & 600 & $0 \cdot 10$ \\
8 & 1200 & $0 \cdot 20$ \\
10 & 1800 & $0 \cdot 30$ \\
\hline
\end{tabular}

is functioning. The experimental design proposed by Taguchi involves using orthogonal arrays to organize the parameters affecting the process and the levels at which they should be varied. Instead of having to test all possible combinations like the factorial design, the Taguchi method tests pairs of parameters. This allows for the collection of the necessary data to determine which factors most affect product quality with a minimum amount of experimentation, thus saving time and resources (Tsao and Hocheng 2007). Taguchi proposed a standard eightstep procedure for applying his method for optimizing any process:

Step 1: Identify the main function, side effects and failure mode.

Step 2: Identify the noise factors, testing conditions and quality characteristics.

Step 3: Identify the objective function to be optimized.

Step 4: Identify the control factors and their levels.

Step 5: Select the orthogonal array matrix experiment.

Step 6: Conduct the matrix experiment.

Step 7: Analyse the data.

Step 8: Predict the optimum levels and performance.

The three variables namely, drill bit diameter $(d)$, spindle speed $(s)$ and feed rate $(f)$ and three levels in each category were considered in this work. The L9 orthogonal array was developed for analysing 3 variables and 3 levels in each variable (Tsao and Hocheng 2007). So, the L9 orthogonal array was selected, and the values are recorded in table 2 . The numbering 1 to 9 represents nine conditions as per table 2 .

\section{Mathematical model of responses}

In statistics, nonlinear regression is a form of regression analysis in which observational data are modelled by a function that is a nonlinear combination of the model parameters and depends on one or more independent variables. The data are fitted by a method of successive approximations. The statistical tool, regression analysis, helps to estimate the value of one variable from the given value of another. In this multiple regression work, three variables are used to predict the responses.

The mathematical relationship for correlating the responses thrust force $(t h)$, torque $(t q)$, tool wear $(t w)$ and the considered process variables were obtained from the coefficients resulting from the Minitab 15 software output. $R^{2}$ values are $0.921,0.997$ and 0.997 for thrust force, torque and tool wear models, respectively.

$$
\begin{aligned}
t h= & 16 \cdot 6+8 \cdot 8 d+0 \cdot 0120 s+83 f \\
& -0 \cdot 00425 d s+0 \cdot 0767 s f-28 \cdot 3 f d . \\
t q= & 2 \cdot 93-0 \cdot 257 d+0 \cdot 000542 s \\
& -1 \cdot 1 f+0.000045 d s+0 \cdot 000700 s f+1.45 f d .
\end{aligned}
$$


Table 2. Recorded values in L9 orthogonal array.

\begin{tabular}{lcccccrr}
\hline $\begin{array}{l}\text { Sl } \\
\text { no. }\end{array}$ & $\begin{array}{c}\text { Drill bit } \\
\text { diameter }(\mathrm{mm})\end{array}$ & $\begin{array}{c}\text { Spindle } \\
\text { speed (rpm) }\end{array}$ & $\begin{array}{c}\text { Feed rate } \\
(\mathrm{mm} / \mathrm{rev})\end{array}$ & $\begin{array}{c}\text { Thrust } \\
\text { force }(\mathrm{N})\end{array}$ & $\begin{array}{c}\text { Torque } \\
(\mathrm{nm})\end{array}$ & $\begin{array}{c}\text { Tool wear } \\
(\mathrm{mm})\end{array}$ & $\begin{array}{c}\text { Chip } \\
\text { formation }\end{array}$ \\
\hline 1 & 6 & 600 & $0 \cdot 05$ & 50 & $2 \cdot 02$ & $0 \cdot 07$ & $\mathrm{C}$ \\
2 & 6 & 1200 & $0 \cdot 35$ & 88 & $1 \cdot 56$ & $0 \cdot 15$ & $\mathrm{D}$ \\
3 & 6 & 1800 & $0 \cdot 20$ & 58 & $2 \cdot 94$ & $0 \cdot 20$ & $\mathrm{CD}$ \\
4 & 8 & 1200 & $0 \cdot 20$ & 52 & $2 \cdot 30$ & $0 \cdot 16$ & $\mathrm{C}$ \\
5 & 8 & 1800 & $0 \cdot 05$ & 55 & $3 \cdot 45$ & $0 \cdot 20$ & $\mathrm{D}$ \\
6 & 8 & 600 & $0 \cdot 35$ & 32 & $1 \cdot 02$ & $0 \cdot 03$ & $\mathrm{CD}$ \\
7 & 10 & 1800 & $0 \cdot 35$ & 49 & $3 \cdot 92$ & $0 \cdot 25$ & $\mathrm{C}$ \\
8 & 10 & 600 & $0 \cdot 20$ & 69 & $1 \cdot 56$ & $0 \cdot 12$ & $\mathrm{D}$ \\
9 & 10 & 1200 & $0 \cdot 05$ & 39 & $2 \cdot 25$ & $0 \cdot 21$ & $\mathrm{CD}$ \\
\hline
\end{tabular}

Table 3. Optimum cutting parameters.

\begin{tabular}{lcccccc}
\hline $\begin{array}{l}\text { Drill bit } \\
\text { diameter }(\mathrm{mm})\end{array}$ & $\begin{array}{c}\text { Spindle } \\
\text { speed }(\mathrm{rpm})\end{array}$ & $\begin{array}{c}\text { Feed rate } \\
(\mathrm{mm} / \mathrm{rev})\end{array}$ & $\begin{array}{c}\text { Chip } \\
\text { formation }\end{array}$ & $\begin{array}{c}\text { Thrust } \\
\text { force }(\mathrm{N})\end{array}$ & $\begin{array}{c}\text { Torque } \\
(\mathrm{Nm})\end{array}$ & $\begin{array}{c}\text { Tool } \\
\text { wear }(\mathrm{mm})\end{array}$ \\
\hline 6 & 600 & 0.30 & $\mathrm{CD}$ & 32 & 1.02 & 0.03 \\
\hline
\end{tabular}

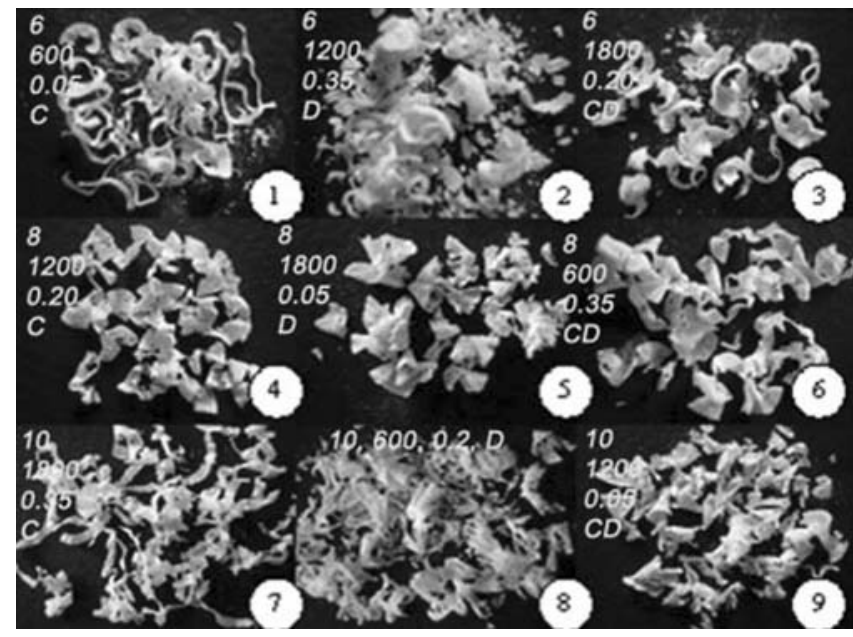

Figure 3. Photograph of chip type as per L9 orthogonal array.

$$
\begin{aligned}
t w= & -0.0324+0.0261 d-0 \cdot 182 f+0.000003 d s \\
& +0.000342 s f-0.0458 f d .
\end{aligned}
$$

The input parameters were drill bit diameter $(d)$, spindle speed $(s)$ and feed rate $(f)$.

\section{Optimization of cutting parameters}

The Taguchi method is a process/product optimization method that is based on eight steps of planning, conducting and evaluating results of matrix experiments to determine the best levels of control factors. The primary goal is to keep the variance in the output very low even in the presence of noise inputs. Thus, the processes/products are made robust against all variations. The desired goal was chosen for each factor and response from the menu.
The possible goals are: maximize, minimize, target, within range, none (for responses only) and set to an exact value (factors only). For optimizing the developed models, the minimum goal was set and executed using Design Expert 7.1.6 software. The optimum values of cutting parameters for minimum responses are given in table 3 .

\section{Results and discussion}

The coir-polyester composites exhibited average values of tensile strength, flexural strength and impact strength of $16 \cdot 1709 \mathrm{MPa}, 29.2611 \mathrm{MPa}$ and $46 \cdot 1740 \mathrm{~J} / \mathrm{m}$, respectively. The optimum set of conditions are used not only for minimum power consumption, minimum cutting forces, minimum tool wear and maximum metal removal rate but also for maximizing hole quality and accuracy. The following results are made based on the result of numerical optimization:

(i) Drill bit diameter of $6 \mathrm{~mm}$ is best suitable one for minimum drilling forces and tool wear in the range of 6 to $10 \mathrm{~mm}$ drill bit diameters.

(ii) Spindle speed of $600 \mathrm{rpm}$ and feed rate of $0 \cdot 30 \mathrm{~mm} / \mathrm{rev}$ may be preferred in drilling of coir-fibrereinforced composites.

(iii) Chip type is another parameter considered in this work because it was produced according to the operating conditions and material properties. The material is prepared and drilling operations are performed, so the operating conditions may be optimized easily. Continuous and discontinuous chip formation was produced for minimum cutting forces and tool wear in HSS tool due to low cutting speed and high feed rate. The chip formation during drilling for various conditions as per L9 orthogonal array is illustrated in figure 3. 
Table 4. Validation of mathematical model.

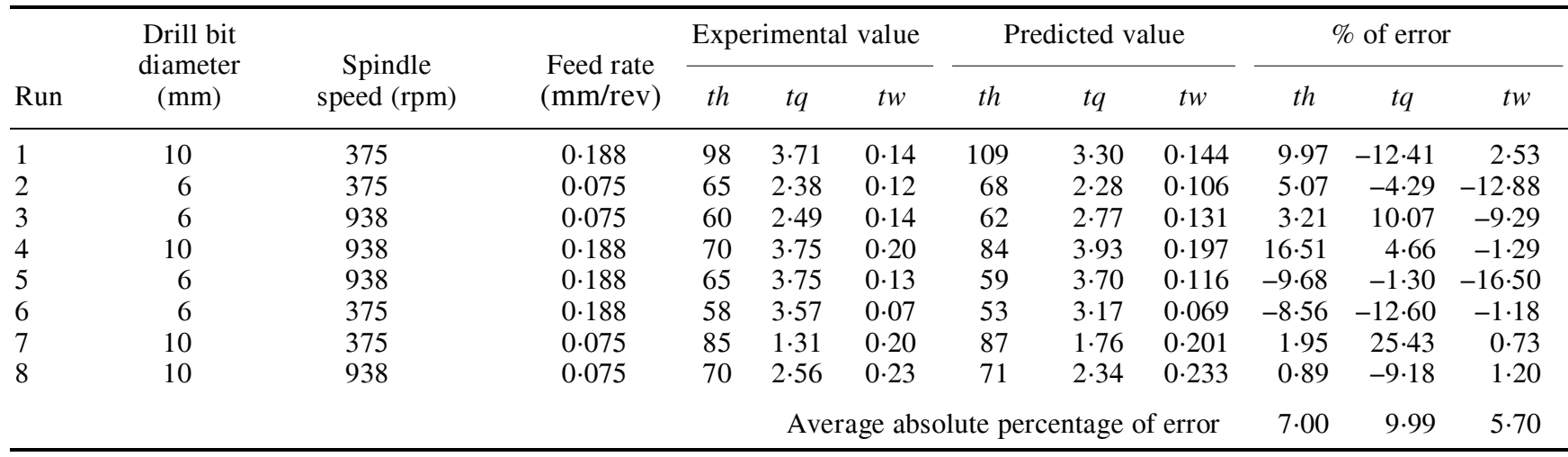

(iv) Confirmation experiments are conducted for eight sets of conditions. The experimental values and the predicted values obtained from mathematical model were compared. The percentage of error was calculated for the validation of mathematical model. It is observed that the average absolute error for thrust force, torque and tool wear are less than $10 \%$, and better accuracy is obtained using the developed mathematical models. The validation of mathematical model is shown in table 4 .

\section{Conclusions}

In this work, the nonlinear mathematical equations of thrust force, torque and tool wear were developed to correlate the important machining parameters in drilling of coir-fibrereinforced composites. The important input variables considered for the present research study is drill bit diameter, spindle speed and feed rate. The influences of all machining parameters on thrust force, torque and tool wear were analysed based on the developed mathematical model. The following conclusions were drawn based on this study:

(I) The procedure can be used to predict the responses for drilling of coir-fibre-reinforced composites within the ranges of variable studied.
(II) The procedure can also be used to find the optimum values of machining parameters for drilling of coir-fibrereinforced composites to reduce tool wear.

\section{References}

Abrao M, Faria P E, Campos Rubio J C, Reis P and Paulo Davim J 2007 J. Mater. Process. Technol. 1861

Fernandes M and Cook C 2006 J. Mach. Tools Manuf. 46 76

Godfrey C, Onwubolu and Kumar S 2006 J. Mater. Process. Technol. 17141

Harish S, Michael D P, Bensely A, Mohan Lal D and Rajadurai A 2009 Mater. Character. 6044

Khashaba U A, Seif M A and Elhamid M A 2006 Composites A38 61

Monteiro S N, Terrones L A H and D'almeida J R M 2008 Polymer Testing 27591

Palanikumar K and Davim P 2008 Mater. Design 28 2008

Palanikumar K, Karunamoorthy L and Manoharan N 2006 J. Reinforced Plastics Composites $\mathbf{2 5} 4$

Tsao C C and Hocheng H 2007 J. Mater. Proc. Technol. 203 342 